Article

\title{
Comparing Discourse and Policy Network Approaches: Evidence from Water Policy on Micropollutants
}

\author{
Simon Schaub ${ }^{1, *}$ and Florence Metz ${ }^{2,3}$ \\ ${ }^{1}$ Institute of Political Science, Heidelberg University, 69115 Heidelberg, Germany; \\ E-Mail: simon.schaub@ipw.uni-heidelberg.de \\ 2 Institute of Political Science, University of Bern, 3013 Bern, Switzerland \\ ${ }^{3}$ Department of Governance \& Technology for Sustainability, University of Twente, 7522 NB Enschede, The Netherlands; \\ E-Mail:f.a.metz@utwente.nl \\ * Corresponding author
}

Submitted: 30 October 2019 | Accepted: 2 May 2020 | Published: 2 June 2020

\begin{abstract}
To understand how actors make collective policy decisions, scholars use policy and discourse network approaches to analyze interdependencies among actors. While policy networks often build on survey data, discourse networks typically use media data to capture the beliefs or policy preferences shared by actors. One of the reasons for the variety of data sources is that discourse data can be more accessible to researchers than survey data (or vice versa). In order to make an informed decision on valid data sources, researchers need to understand how differences in data sources may affect results. As this remains largely unexplored, we analyze the differences and similarities between policy and discourse networks. We systematically compare policy networks with discourse networks in respect of the types of actors participating in them, the policy proposals actors advocate and their coalition structures. For the policy field of micropollutants in surface waters in Germany, we observe only small differences between the results obtained using the policy and discourse network approaches. We find that the discourse network approach particularly emphasizes certain actor types, i.e., expanders who seek to change the policy status quo. The policy network approach particularly reflects electoral interests, since preferences for policies targeting voters are less visible. Finally, different observation periods reveal some smaller differences in the coalition structures within the discourse network. Beyond these small differences, both approaches come to largely congruent results with regards to actor types, policy preferences and coalition structures. In our case, the use of discourse and policy network approaches lead to similar conclusions regarding the study of policy processes.
\end{abstract}

\section{Keywords}

agenda-setting; discourse network analysis; micropollutants; policy change; policy network analysis; risk governance; water policy

Issue

This article is part of the issue "Policy Debates and Discourse Network Analysis" edited by Philip Leifeld (University of Essex, UK).

(C) 2020 by the authors; licensee Cogitatio (Lisbon, Portugal). This article is licensed under a Creative Commons Attribution 4.0 International License (CC BY).

\section{Introduction}

The network lens is an analytical approach to policymaking, which emphasizes that policies are adopted in a bargaining process between multiple actors. These actors participate in advocating and formulating policies and include political parties, interest groups or administrative units. As no single actor has sufficient decision-making power, scholars adopt the network lens to uncover the complex interdependencies among actors in policymaking processes. Scholars of policy process have employed the network approach as an analytical tool either: a) to describe the variety of actors, their policy positions and their relationships to one another; or b) to determine an- 
alytically how actors' interactions shape the outcomes of policymaking processes (Howlett, 2002).

As popularity for the network lens has increased, so too have the number of different network approaches (Adam \& Kriesi, 2007; Börzel, 1998). One important strand of the literature draws attention to 'policy networks.' Policy networks are defined as entities composed of organizations involved in the formulation or implementation of public policies (Fischer, 2017). The concept has its roots in the literature on the organizational state (Laumann \& Knoke, 1987) and collective action (Laumann, Pappi, \& Rossi, 1976). According to this literature a multitude of actors participates in policymaking. The actors depend on each other to make collective decisions. These interdependencies are conceptualized in networks by nodes and ties. Examples of nodes in policy networks are interest groups, political parties, administrative units, experts, and other actors involved in policy processes. These can be linked by ties of cooperation, information exchange or conflict. In this article, we adopt a narrow definition of policy networks by focusing on actors solely involved in policy formulation, i.e., the production of policy outputs. The policy network approach serves to systematically test theoretical mechanisms guiding the production of policy outputs.

Another body of literature focuses on 'discourse networks' (Leifeld, 2017). While the literature on discourses is broad, its various strands converge on the claim that discourses matter in politics. Verbal interventions constitute important elements of political mobilization, conflict and decision-making (Leifeld \& Haunss, 2012). Classic works on critical discourse analysis (Foucault, 1991) and deliberative democracy (Habermas, 1981) paved the way for more empirical analytical approaches, such as the discourse network approach. Discourse networks are defined as verbal interactions between political actors which make public statements conditional on each other about a given policy (Janning, Leifeld, Malang, \& Schneider, 2009; Leifeld, 2016, 2017). Accordingly, actors constitute the nodes in discourse networks, while shared policy preferences expressed via public statements represent the ties. The discourse network approach is an analytical tool used to systematically test the theoretical mechanisms guiding the development of policy debates.

Both discourse and policy network approaches have been used to elucidate the policymaking process, but it remains unclear whether both approaches yield similar results regarding policy change. For example, Leifeld (2013) and Bulkeley (2000) analyze policy change by studying the formation of coalitions based on the discourse network approach, while Ingold (2011) and Fischer (2014) employ the policy network approach for the same purpose. It remains unclear whether such studies would have come to the same results if they had used the respective other approach. To close this research gap, we ask: Which aspects of policy change do the different analytical frameworks emphasize?
This article compares similarities and differences between the two types of network approaches in four steps: First, we analyze differences in the participation of actors. Some scholars conceptualize discourses and policy processes as two different arenas of political participation (Binderkrantz, Christiansen, \& Pedersen, 2015; Wolfe, Jones, \& Baumgartner, 2013). Organizations may opt to participate in the discourse if they do not have access to formal decision-making. We therefore compare how accessible both types of networks are to different actors.

Secondly, we compare policy preferences of actors. Studies on discourse networks have relied on the content analysis of texts, e.g., media articles or parliamentary debates, in order to gather data on actors participating in the discourse and their policy preferences (Fisher, Leifeld, \& Iwaki, 2013; Leifeld, 2013). By contrast, numerous studies on policy networks have relied on surveys (e.g., Henry, 2011; Ingold \& Fischer, 2014). Here, we compare actors' policy preferences in discourse and policy networks in order to understand whether results differ systematically.

Thirdly, we scrutinize the formation of coalitions. Coalitions refer to subgroups of actors with shared policy preferences (Fischer, 2017). Actors form coalitions as a strategy to pool resources among likeminded others and influence policymaking in line with their preferences. In policy processes, it is typical for several competing coalitions to exist, such as a pro-change and a pro-status quo coalition. Here, we analyze whether discourse and policy networks fall into the same coalition structures. With structures, we mean the overall existence, number and strength of competing coalitions rather than the composition of coalitions. Consequently, the same coalition structures (e.g., two opposing coalitions) can be in place, even if coalitions themselves are not composed of the same actors.

Fourthly, we investigate the degree to which different observation periods influence results. The policy cycle model conceptualizes policymaking as a series of consecutive stages (Easton, 1965). Networks that reflect the agenda-setting phase of the policy process may look different to those that capture the decision-making phase. Time-stamped data are available for discourse networks, which rely on coded media data, but are difficult to gather for policy networks, which rely on survey data. We compare differences between discourse networks analyzed over time and policy networks for one point in time.

We rely on a case from German water protection policy. An emerging issue in water protection concerns micropollutants, i.e., chemical substances that end up in water bodies in small concentrations but nevertheless raise concern due to their potential adverse health effects on humans and the environment (Metz, 2017). Actors involved in policy discourse and policy formulation have debated on how to address the issue. Potential policy solutions address consumers, agriculture or industry in order to reduce the use of potential pollutants at the source. An alternative policy approach addresses the 
problem from the 'end-of-the-pipe' by treating polluted wastewater in sewage plants (Triebskorn et al., 2019).

The goal of this study is to uncover differences and similarities between discourse and policy networks in order to comprehend whether both types of analyses produce similar results regarding policy change in democratic states. This article provides researchers with insights into three key aspects of policy change: a) the accessibility of policy venues (discourse/policy formulation) to actors; b) policy proposals actors advocate; and c) coalition structures. These insights should improve researchers' understanding of what they can infer about policy processes from the data they have gathered. Providing clarity is relevant in order to understand whether both network approaches can be used to answer similar research questions and empirically test the same theories.

\section{Expectations of Differences and Similarities between the Network Approaches}

\subsection{Actor Participation}

The literature on agenda-setting and policy narratives suggests that we can expect differences between discourse and policy networks (Baumgartner, Berry, Hojnacki, Leech, \& Kimball, 2009; Jones, McBeth, \& Shanahan, 2014). We argue that these differences can be attributed to the differences in actor participation between the two networks.

The idea underlying why actors participate in policy discourse is that they try to influence public opinion in order to affect the dynamics of political competition (Tosun \& Schaub, 2017). The literature of comparative politics has shown that public opinion influences policy decisions (Mühlböck \& Tosun, 2018; Wlezien, 2004). Based on the work of Schattschneider (1960) and Baumgartner et al. (2009), one can infer that not every actor in a policy field is interested in participating in the discourse and drawing attention to a policy issue. Politics is conceptualized as a conflict in which competing actor coalitions strive to influence policymaking (Weible, Sabatier, \& McQueen, 2009). Depending on whether these actor coalitions aim for policy change or to preserve the status quo, they tend to use different strategies and use different venues (Baumgartner et al., 2009; Jones et al., 2014). Actors can be categorized as 'containers' and 'expanders' (Cobb \& Coughlin, 1998; Jones et al., 2014). 'Containers' are actors with an interest in preserving the policy status quo. They typically aim to minimize the level of public attention on an issue and, therefore, avoid participation in a public discourse. Regarding environmental policy, industrial associations are less likely to participate in the discourse because they try to avoid public attention that could result in stricter regulation. Instead, these actors prefer to establish direct links to decision makers and exert influence in policy networks through participation in 'polycentric' institutional arrangements (Fischer, Angst,
\& Maag, 2017; Leifeld \& Schneider, 2012). This especially holds true in corporatist political systems (Christiansen, Mach, \& Varone, 2018). On the contrary, 'expanders' are actors with an interest in changing the policy status quo, though they often have limited access to decision makers and policy networks or find themselves in a weak bargaining position. In their need to adapt and use different strategies, these actors resort to public discourse. In environmental policy, these actors are usually environmental or consumer protection organizations with an interest in stricter regulation (Tosun \& Schaub, 2017). For such new or marginalized actors, public discourse is a venue comparatively easy to access. Their goal is to steer public opinion by dominating the discourse and attracting media attention, since this exerts pressure on decision makers (Baumgartner et al., 2009; Jones et al., 2014; McCombs \& Shaw, 1972). Based on these considerations, we assume that both network approaches reveal some differences with regard to the actors participating in policymaking:

Expectation 1a: The policy network approach should emphasize the participation of containers in the policymaking process;

Expectation 1b: The discourse network approach should emphasize the participation of expanders in the policymaking process.

In addition, we expect both approaches to reveal similarities concerning the participation of politicaladministrative actors, which are usually central to both policy and discourse networks. Policy networks represent the venue in which these actors typically play an important coordination role. Additionally, politicaladministrative actors tend to participate in public discourse, often in an effort to sensitize the population. Therefore, we categorize these actors as a third group and expect both approaches to reveal their presence:

Expectation 1c: Discourse and policy network approaches should equally emphasize the participation of political-administrative actors in the policymaking process.

To summarize, we expect any study employing either the discourse or the policy network approach to reveal differences in the types of actors participating in policymaking. Participation depends on whether actors want to preserve or change the policy status quo. Only political-administrative actors are expected to be present in equal degrees.

\subsection{Actors' Policy Preferences}

Discourses in democratic countries ideally resemble deliberative arenas, while policy processes have to follow stricter institutional rules. In the ideal model of a deliberative democracy (Habermas, 1996), actors can freely par- 
ticipate in discourses. In a policy debate, state and nonstate actors can participate and express their preferences based on their causal beliefs. The discourse network approach should, therefore, represent a broad spectrum of actors and policy proposals.

By contrast, policy processes are governed by formal and informal rules of participation that restrict access to decision-making and, thereby, the spectrum of discussed policy proposals. Formal rules attribute decision-making power and responsibility for the design and content of policies to elected state actors (Moe, 1990; Trebilcock \& Hartle, 1982). Informal rules provide a few non-state actors, which have a stake in or knowledge on a particular policy issue, with access to policy processes. In the formal policymaking process, actors are less likely to propose unpopular policies that target their respective constituency, because it can be costly for target groups to implement such a policy (Metz \& Ingold, 2017). Since elected state actors are dependent on votes, they are unlikely to express policy preferences that target their electorate and would impose costs on their voters. In fact, German citizens disapprove of policy measures such as taxes or fees that would entail personal costs (Tosun, Schaub, \& Fleig, 2020). Likewise, non-state actors are likely to block policies that would impose the burden of implementation on the economic or civil society groups whose interests they represent. We expect the network approach to reflect the vested interests of those actors which have access to policy formulation. Policy proposals that do not meet the interests of respective electoral, corporate or civil society interests are likely to be neglected or rejected.

Expectation 2: The policy network approach should more strongly reveal policy preferences that reflect respective electoral, corporate or civil society interests than the discourse network approach.

\subsection{Coalitions}

The concept of 'coalitions' is central to theories of policy process, e.g., the 'Advocacy Coalition Framework' (Sabatier \& Jenkins-Smith, 1999), and argumentative discourse analysis (Hajer, 1993). Actors express their policy preferences in discourses and during policy formulation, and they form coalitions based on shared preferences (Leifeld, 2013; Sabatier, 1987). Opposing coalitions compete for influence on policy outputs. The coalition that dominates the discourse or policy formulation respectively has the greatest potential to shape policy outputs.

We distinguish between three ideal types of coalition structures in Figure 1 (Ingold \& Gschwend, 2014): Adversarial structures with opposing coalitions and little coordination; collaborative structures with opposing but coordinated coalitions; and unitary structures consisting of one dominant coalition.

Similar coalition structures should, in principle, be observable across discourse and policy networks. In
Ideal network structures

Adversarial

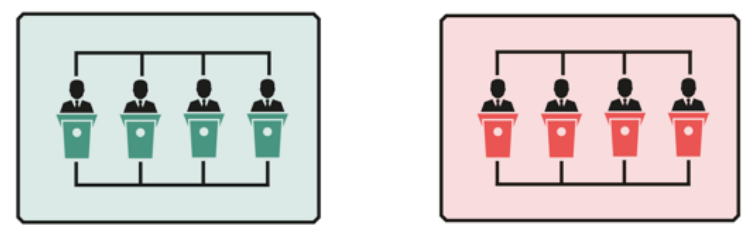

Collaborative

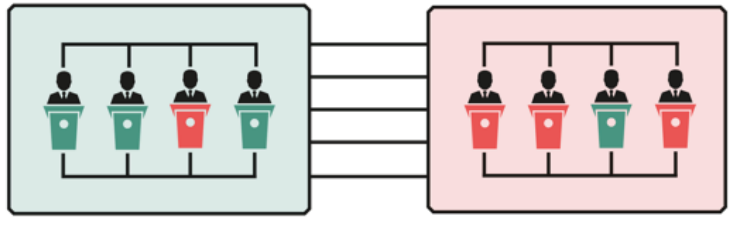

Unitary

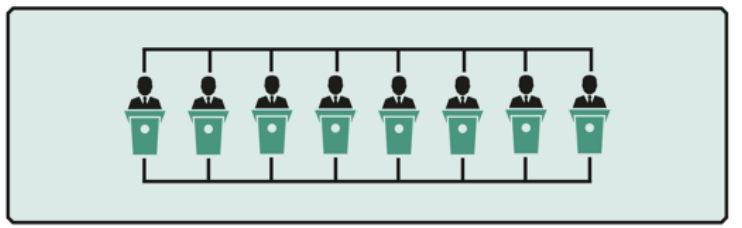

Figure 1. Three coalition structures. Source: Metz (2017).

Expectations 1a and 1b, we explained that discourse and policy network approaches are likely to reveal different actor types in policymaking. Despite such differences in participation, it is possible that both network approaches lead to the identification of similar coalition structures (adversarial, collaborative or dominant coalitions), because they each reveal the same underlying lines of conflict that shape the formation of coalitions. For example, both approaches could reveal a dominant pro-change coalition if the majority of actors in the policy discourse and in policy formulation expresses a clear preference for policy change. In both analyses, a majority of actors would cluster around pro-change preferences. We therefore expect the following similarities:

Expectation 3: Discourse and policy network approaches should reveal similar coalition structures.

\subsection{Differences in Time}

In his analysis of a discourse network, Leifeld (2013) observes the evolution of the policy process from one unitary coalition towards a bipolarized discourse, and then back to a new, dominant, advocacy coalition. These observations suggest that the discourse network approach highlights the evolution of political conflict between coalitions over time.

Observing the evolution of policy processes over time is possible with time-stamped discourse data (Leifeld, 2017), but rarely feasible with policy network data. To date, the most widely applied method for gathering data on policy networks is through surveys. One would need to survey actors repeatedly in order to cap- 
ture the evolution of the policy process over time, but such repeated surveys are rarely possible due to resource constraints and the objections of respondents to repeated participation (exceptions include Ingold \& Fischer, 2014). To overcome this difficulty, survey data tend to capture the aggregate of actors' policy preferences and interactions during the entire policy process or during the phases that precede the survey. Due to cognitive constraints and recall difficulties, it is plausible that data on policy networks capture the phase of the policy process in which the survey took place. If the survey took place during polarization, the coalition structure of the policy networks will capture this particular point of the policy process. Our data-related expectation is as follows:

Expectation 4: Different results between policy and discourse network approaches are due to different measurement, time and data collection methods.

To summarize, we formulate four expectations regarding the similarities and differences in actor participation, policy preferences and coalition formation. Whereas the first two expectations are derived from theory, the latter two stem from methodological considerations.

\section{Case, Data, and Methods}

\subsection{Case}

In this study, we compare policy and discourse networks in the new emerging policy field of micropollutants in surface waters in Germany. These networks are built on actors' preferences towards four different policy solutions for mitigating micropollution. We observe actors' preferences through a survey in order to construct the policy network, and through the coding of newspaper articles in order to construct the discourse network.

\subsection{Data}

\subsubsection{Discourse Network}

To analyze the discourse on micropollutants, we selected newspaper articles published in the nation-wide newspaper Frankfurter Allgemeine Zeitung and in at least one principal regional newspaper from each of the German states (23 newspapers in total). Relevant articles were identified by using a keyword search within the respective newspaper archives. Overall, we identified 1069 relevant articles on micropollutants between January 2013 and March 2017. The number of articles per newspaper ranges between 17 and 124 . Most of the articles stem from the regional newspapers, and the geographic distribution is fairly even (see figures and tables provided in Appendix A in the Supplementary File for details). Due to duplicate articles that reproduced information provided by the German news agency dpa (Deutsche PresseAgentur), we reduced our final sample to 770 articles.
Within these articles, we coded statements that actors made on micropollutants in surface waters. More specifically, we coded whether actors agreed or disagreed with the same four policy solutions that were also put forward in the discourse: a) addressing consumers; b) taking measures in the agricultural sector; c) adapting industrial production; and d) improving filtering in sewage treatment plants (end-of-pipe). Statements were coded using the software Discourse Network Analyzer (Leifeld, Gruber, \& Bossner, 2019). One of the authors and two research assistants coded the statements to ensure reliability. After coding, 63 of originally 173 actors were selected as relevant. Relevant actors are defined as organizations that are politically active across Germany or which issued at least two statements at different points in time during the observation period (see also Leifeld, 2017, on applying thresholds for participation in discourse). Selected actors issued 303 statements in total.

\subsubsection{Policy Network}

In 2014, we surveyed all the state and non-state actors which had participated in the legal revision of the German Surface Water Ordinance since 2008 (see Metz, 2017 , for a description of the policy process and the actor identification method). With a response rate of $68.4 \%$, we obtained policy preference data for 27 actors. In the survey, we asked respondents to indicate their level of agreement with the following statements on a four-point Likert scale: a) Reducing pharmaceutical micropollution is a consumer responsibility; b) micropollution is a responsibility of agricultural policy, c) micropollution is a responsibility of chemical policy (in order to adapt industrial production); d) measures should be end-of-pipe. Usually, the policy network approach links actors by ties of cooperation or information exchange. In this study, the policy network is built on shared policy preferences to enhance comparability with the discourse network approach. The data were not originally collected for this comparative study; however, the comparison is possible as both the survey questions and the statements coded in the discourse measure the same concepts, i.e., actors' preferences regarding the same four policy solutions.

\subsection{Methods}

We apply network methodology as well as descriptive statistics to test the plausibility of our theoretical and data-related expectations. Given its' small-N research design, our study constitutes a plausibility probe, i.e., a pre-test for future theory development (Levy, 2008). In order to probe Expectations 1 and 2, we compare actor types and their policy preferences across policy and in discourse networks. We classify all actors representing the chemical and pharmaceutical industry as well as the agricultural sector as containers since we expect these to have an interest in preserving the policy status quo. Conversely, environmental and consumer protec- 
tion organizations, green political parties and actors from the wastewater treatment sector were categorized as expanders since these can be expected to have an interest in changing the policy status quo. Political-administrative actors include different governmental institutions and agencies. Third-party actors include all organizations for which no clear preference towards changing or preserving the policy status quo can be expected (see Tables B1 and B2 in the Supplementary File for an overview of the actors and their membership).

For Expectations 3 and 4, we compare the structure of both networks. First, we compare the policy and the discourse networks based on the full observation period (Expectation 3). In a further step, we divide the discourse network into two observation periods ranging from 2013 to 2014 and 2015 to 2017 and then compare both discourse networks with the policy network captured in the period before 2014 (Expectation 4). Precisely, we compare one-mode networks in which actors are linked depending on whether they share preferences with regard to the four policy solutions. We compute these separately for the policy network and discourse network data. The resulting matrices contain actors in rows and columns, with cell values indicating the degree of shared policy preferences. High values indicate high similarity and low values low similarity. More specifically, we analyze 'subtract' networks; these are created by combining 'congruence' and 'conflict' networks, which means that they include both agreement and disagreement on policy solutions. In congruence networks, actors are linked if they co-support or co-reject a policy proposal. In conflict networks, actors are linked if one actor supports while the other opposes a policy. The subtract network then combines both ap- proaches by subtracting conflict network ties from congruence network ties (Leifeld, 2017). To improve the comparability of discourse and policy networks, we normalized both networks via the 'jaccard similarity measure' (see Leifeld, 2017, and Leifeld et al., 2019, for discourse network normalization). We graph the networks by placing actors as nodes in a two-dimensional space based on their connectedness. Nodes are linked by edges if they share policy preferences. Negative edges indicating conflicting policy preferences had been removed beforehand (see Nagel, 2016, for a similar application). This approach allows researchers to evaluate the structure of networks and to identify actor clusters, since actors with higher degrees of similarity are placed closer to each other (Leifeld et al., 2019). Finally, we compare differences in subgroup structures within the networks by conducting a cluster analysis (Leifeld et al., 2019). More specifically, we apply hierarchical cluster analysis using Ward's optimization method in order to probe Expectation 3 (Jain \& Dubes, 1988). To compare the two observation periods of discourse networks, we detect communities by using the 'spinglass' algorithm (Reichardt \& Bornholdt, 2006).

\section{Results and Discussion}

\subsection{Actor Participation}

We expected the policy network approach to emphasize the participation of containing actors more strongly than the discourse network approach (Expectation 1a). Conversely, we expected the discourse network approach to emphasize expanding actors (Expectation 1b). Figure 2 portrays the share of containers, expanders,

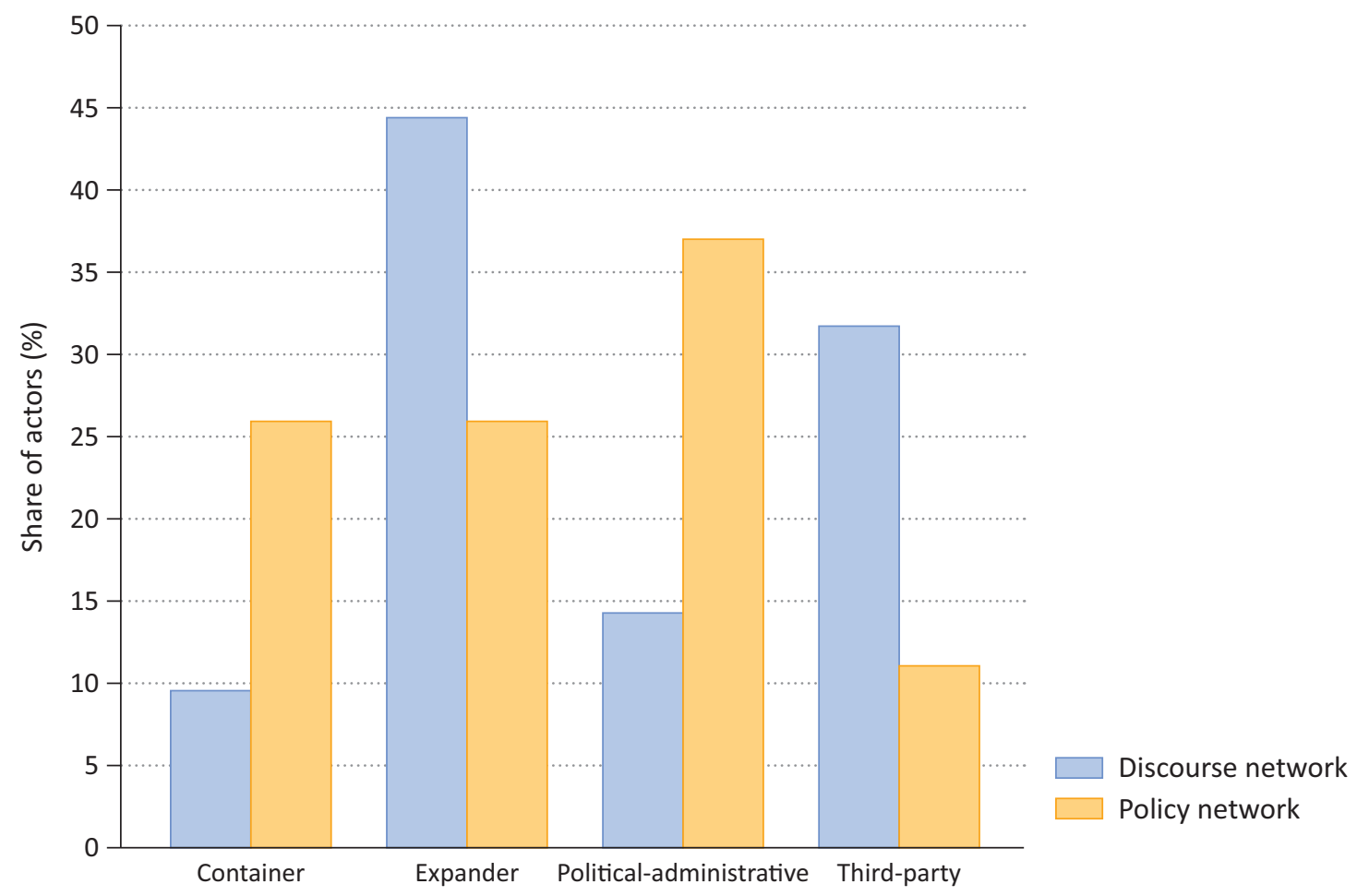

Figure 2. Emphasis of different actor types. 
political-administrative and third-party actors. The results support Expectations $1 \mathrm{a}$ and $1 \mathrm{~b}$. The policy network reveals a larger share of containing actors (ca. 25\%) compared to the discourse network (ca. 10\%). The discourse network emphasizes expanding actors more strongly (ca. $45 \%$ ) than the policy network (ca. $25 \%$ ). However, Figure 2 also shows that the share of containers and expanders in the policy network is about equal. This might be a result of the efforts of political-administrative actors to include every relevant stakeholder in the policy formulation process. Thus, differences in emphasis can mostly be traced back to the discourse network, which aligns well with our theoretical argument.

Both networks reveal the presence of politicaladministrative actors, which is in line with our theoretical expectation. However, they are more pronounced in the policy network. The discourse network is characterized by a larger share of third-party actors. This is mainly due to the larger number of scientific institutions present in the discourse.

Figure 3 gives further details on actors' affiliations and their relative frequency within both networks. The policy network is characterized by a larger share of organizations that are affiliated with the agricultural and industrial sectors, which mostly explains the differences in containers between both approaches. The share of political-administrative actors from federal, state and regional levels is also larger, which can be explained by their coordination role in the policy network. The discourse network emphasizes political parties more strongly, mainly the German Green Party (Alliance 90/
The Greens). Political parties are not represented in the policy network, because the legal proposal was exclusively discussed in the parliamentary chamber that represents the German states (German Bundesrat). Rather surprisingly, the share of environmental organizations is equal. However, this observation fits the presumption that political-administrative actors strived to include every relevant stakeholder in the legal revision.

To summarize, the policy and the discourse networks differ in their emphasis on containing and expanding actors. These differences are mostly due to the unequal distribution in the discourse network (blue bars in Figure 2). As expected, political-administrative actors are present in both networks.

\subsection{Actors' Policy Preferences}

Discourse and policy networks are expected not only to differ in the composition of actor types but also regarding actors' policy preferences. Specifically, we expect the discourse network to be more open to discussions on policies that are aimed at target groups, such as consumers or voters. Figure 4 depicts the share of actors that agree or disagree with each of the four discussed policy solutions in both networks.

First, we report differences in the data underlying policy and discourse network analysis. Whereas in policy networks most of the surveyed actors took a position on all four policy solutions, the discourse network is characterized by a large share of 'missing' information. Many actors present in the discourse only positioned themselves

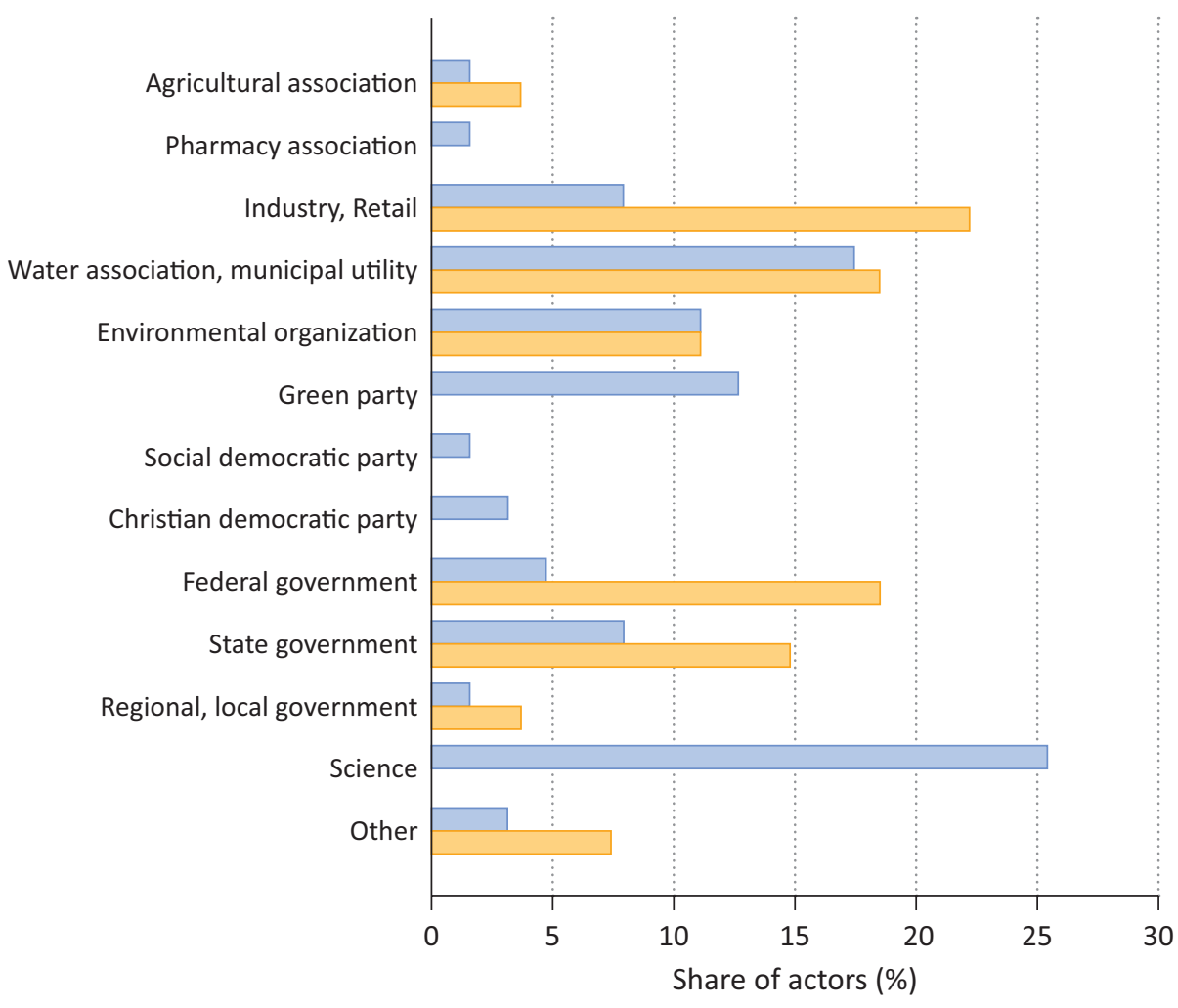

Discourse network

Policy network

Figure 3. Presence of different actors. 


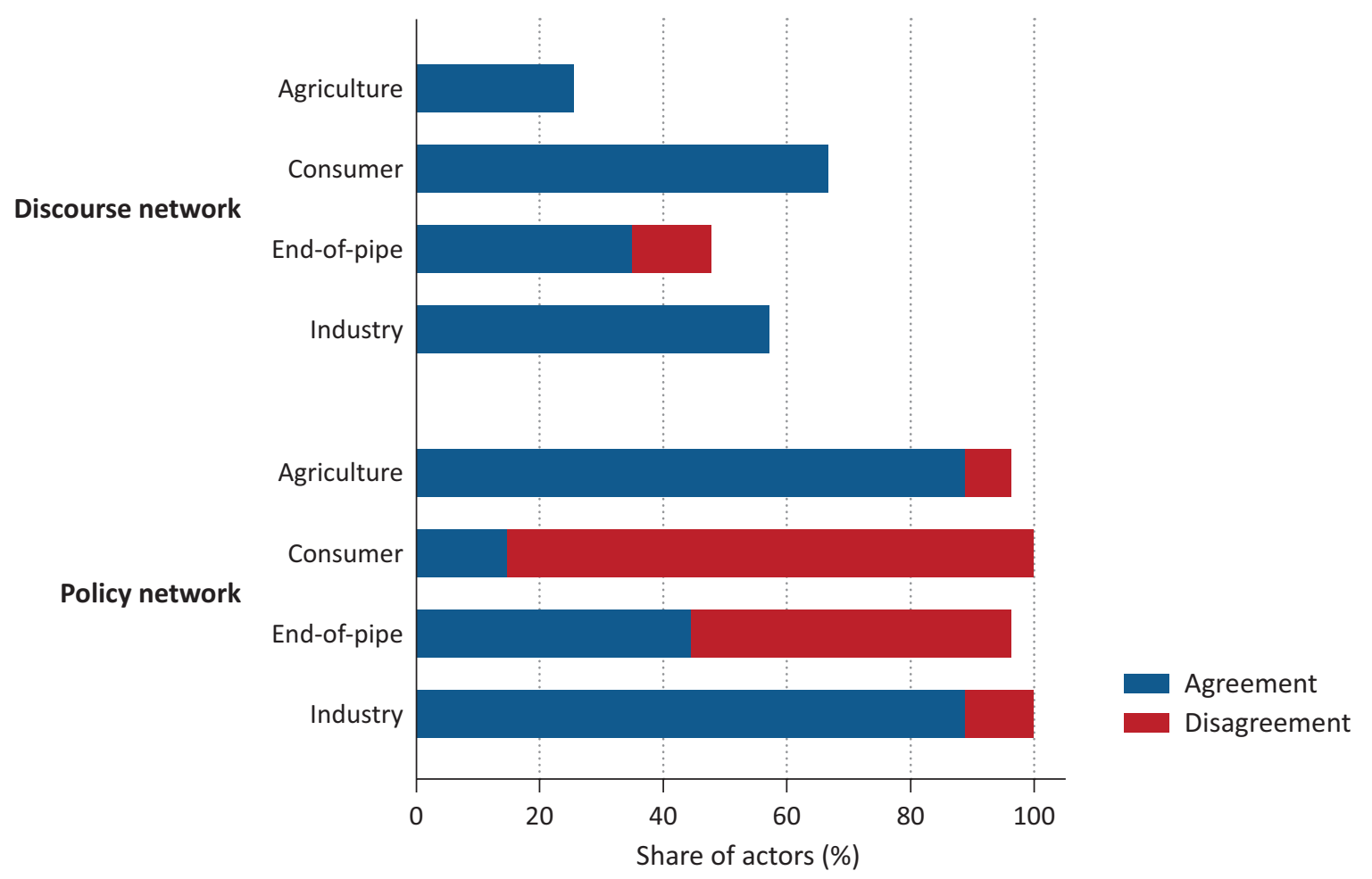

Figure 4. Agreement and disagreement on policy preferences.

on one or two of the discussed policy solutions. The differences can be traced back to the different types of data collection. Whereas surveys ask actors to indicate their preferences (agreement or rejection) from a predefined list, the discourse network approach only captures the spectrum of preferences that actors formulate. Second, and contrary to the policy network, the discourse network reveals mostly 'positive' statements in which actors indicate agreement with policy solutions.

Regarding our theoretical considerations, the policy preferences revealed by both network approaches are surprisingly similar. Agreement with measures addressing the agricultural and industrial sector is high in both networks (at least among those actors that made a statement on these measures within the discourse). Disagreement with end-of-pipe solutions is stronger in the policy network. Here, actors are divided on the question of whether end-of-pipe measures are best for mitigating the entry of micropollutants, with around $44 \%$ agreeing and $52 \%$ disagreeing. We can mainly observe differences between the approaches in the measures that address consumers. Here, opposition is stronger in policy networks; this might be due to electoral concerns as actors wish to avoid increasing costs for voters.

To summarize, we can observe differences in the positions taken in both networks. As predicted in Expectation 2, policies targeting consumers, i.e., voters, are less prominent in the policy than in the discourse network, which may be due to electoral concerns. Apart from this difference, similarities among the policy proposals put forward in both networks are surprisingly high. In contrast to Expectation 2, results do not particularly emphasize the policy preferences of corporate interests in the policy network. In the latter, only few actors reject policies targeting agriculture or industry.

\subsection{Coalitions}

We expected discourse and policy networks to reveal similar network structures regarding the formation of coalitions. Figure 5 gives a first visual impression of the structure and the composition of subgroups within both networks.

Polarization in the discourse network is rather low. In fact, most actors cluster in the middle as they share policy preferences with many other actors within the network. There are only a few actors which form small opposing clusters that surround one big cluster in the middle. The gradual removal of links between actors with lower weights, i.e., fewer shared policy preferences, substantiates this impression (see the network graphs in C1 in the Supplementary File). However, we can observe that four of the six containers form a separate cluster, indicating some divergence between containing and expanding actors. Nevertheless, the network indicates a higher degree of consent than conflict. Therefore, we conclude that the discourse network is characterized by a unitary or strongly collaborative structure.

The structure of the policy network is similar. The network consists of one large group of actors in the center of the graph. Within this center, two subgroups exist. Within these subgroups, edge weights are higher, indicating a slightly higher degree of preference similarity (see also the network graphs in B2 in the Supplementary File). 


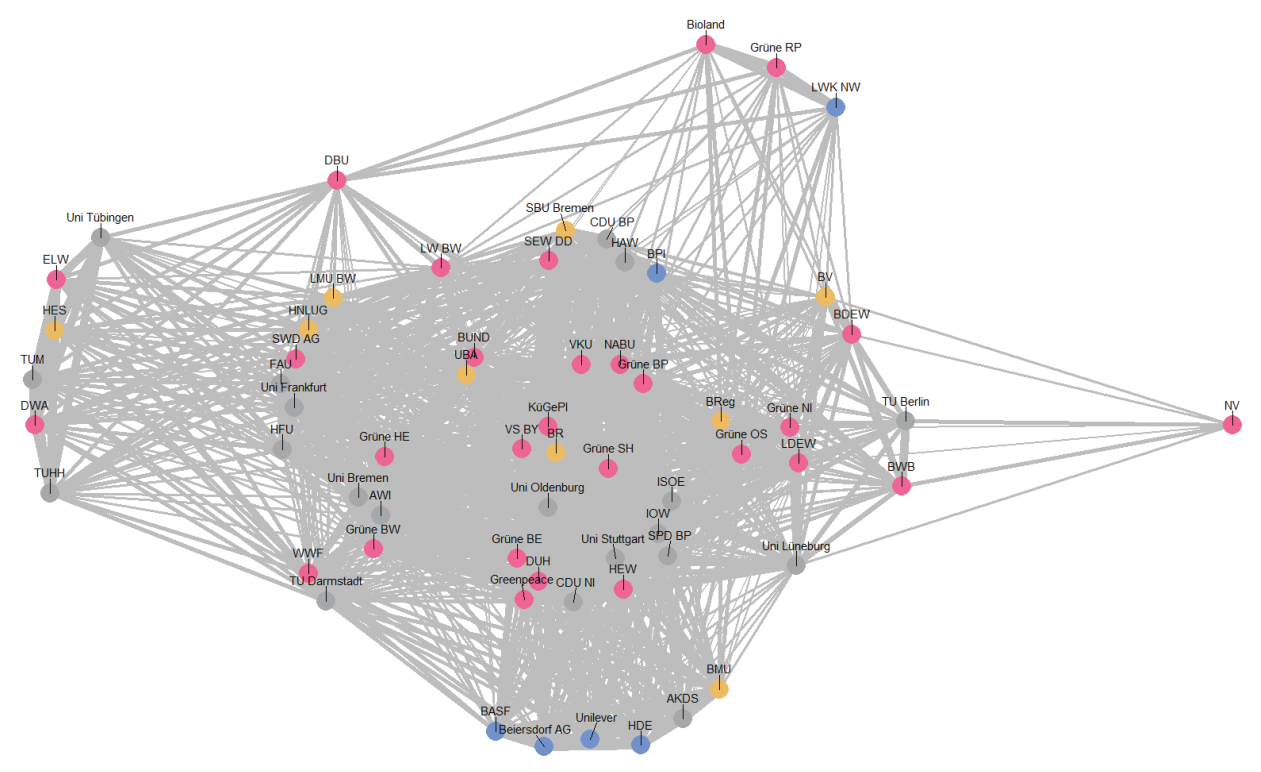

- Container

- Expander

- Political-administrative

- Third-party

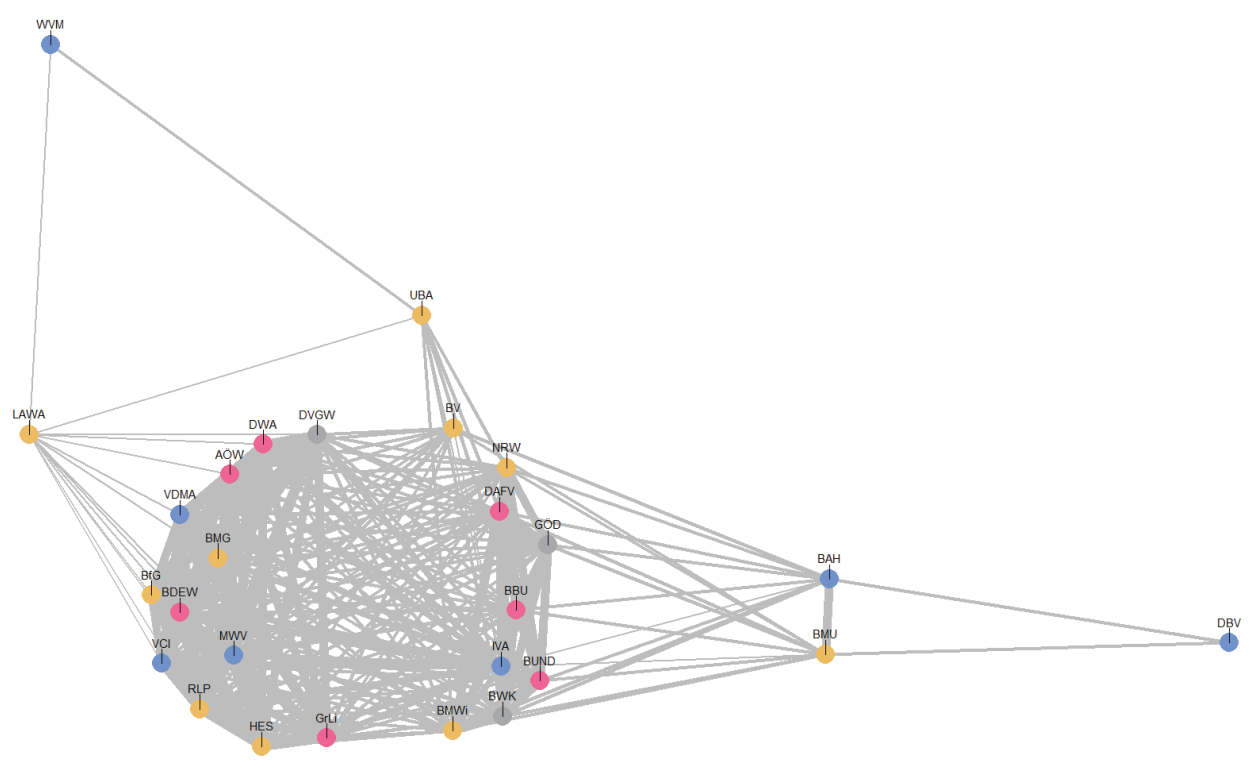

(b)

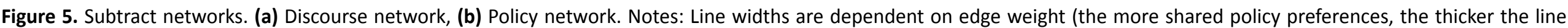
between two actors). Actors have been positioned using the Fruchterman-Reingold algorithm. 
Much like the discourse network, there are many links between the subgroups, indicating that polarization is not very strong. Regarding actor types, expanding and containing actors do not cluster in separate groups, which further indicates an absence of conflict. Overall, we can conclude that the policy network also reveals a unitary or strongly collaborative structure.

The results of the hierarchical cluster analysis substantiate the conclusions drawn from our first analysis of the network structures. Figure 6 depicts the results as a dendrogram in which similar actors are grouped together as clusters. The height of the branches displays the similarity or dissimilarity of actor groups. The lower the branches connecting two clusters, the more similar they are. The heat map located underneath the dendrogram illustrates each actor's positioning on the policy solutions discussed.

The discourse network is characterized by a larger number of smaller cliques with unique policy preferences, rather than adversarial coalitions. This impression prevails upon closer inspection of the actor groups' shared policy preferences in the heat map. One group of actors on the left mostly agrees on solutions that either address consumers or apply an end-of-pipe approach. In the middle, one group opposes an end-of-pipe approach and another one only favors solutions targeting the industrial or the agricultural sector. There is one larger group on the right which supports solutions addressing consumers and the industrial sector. Finally, there are a few smaller groups with actors which support solutions targeting the industry but differ in their preference towards other solutions.

The policy network consists of two groups of actors, though actors in both of these groups have very similar policy preferences. Most actors support measures in the agricultural and industrial sector and oppose policies that address consumers. The two groups only emerge as distinct from one another due to their divergent positions on the question of whether end-of-pipe measures should be prioritized. While the group on the left opposes the prioritization of end-of-pipe measures, the group on the right remains mostly supportive. Overall, the results of the cluster analysis also indicate a unitary structure.

To summarize, policy and discourse networks reveal similar coalition structures. Both are characterized by a unitary or strongly collaborative structure. Observed differences between networks are rather small.

\subsection{Differences in Time}

Turning to Expectation 4, we split the discourse network into two periods and analyze whether significant differences in network structures can be observed.

Figure 7 depicts the subtract networks for both periods and the results of community detection (node colors). When looking at clusters, the network in Period 2 (January 2015-March 2017) is less polarized than in pe- riod 1 (January 2013-December 2014). The results of community detection also suggest differences in the network structures. The analysis reveals three larger and one very small group in the first period. In the second period, we identify four groups. However, the positions of these groups overlap to a large degree. The higher number of policy preferences shared by members of different groups in the second period indicates that similarity between groups (between-group density) increased compared to in the first period. This further points towards an evolution of network structure over time.

The results of hierarchical cluster analyses and closer inspection of the specific policy preferences substantiate these observations (see the dendrograms and heat maps in Figures E1 and E2 in the Supplementary File) since congruence between the actors increases over time. Actors are less divided concerning measures in the agricultural or industrial sectors in Period 2. Instead, the question of whether end-of-pipe measures should be prioritized is now more prominent in Period 2 and divides some of the actors. In this regard, Period 2 of the discourse network resembles the policy network more closely as divisions on this policy solution coincide with the main line of conflict in the policy network.

To summarize, we can observe some small differences between both observation periods. In fact, the structure of the discourse network in the second period resembles the policy network more closely. Although the differences are not very strong, it is noteworthy that different time periods may lead to different results. These findings suggest that data collection for policy networks at different points in time could most likely also increase the accuracy of results. This especially holds true when analyzing policymaking processes that stretch over a longer period of time.

\section{Conclusions}

Both policy and discourse network approaches are used to analyze policymaking processes, but there is a lack of empirical studies comparing the similarities and differences in results that these approaches reveal regarding policy change. While policy networks often build on survey data, discourse networks typically employ media data to capture actors' shared policy preferences. In order to make an informed decision on valid data sources, researchers need to understand how differences in data sources may affect results. As this remains largely unexplored, we systematically compared policy and discourse networks by taking the case of water policy in Germany.

In a first set of theoretical expectations, we explored differences based on the idea that discourses may represent a more deliberative process, open to marginalized actors and various policy proposals, compared to policy networks. In a second set of expectations, we investigated similarities, i.e., whether similar coalition structures of actors with shared policy preferences emerged in both types of networks. 
Discourse network

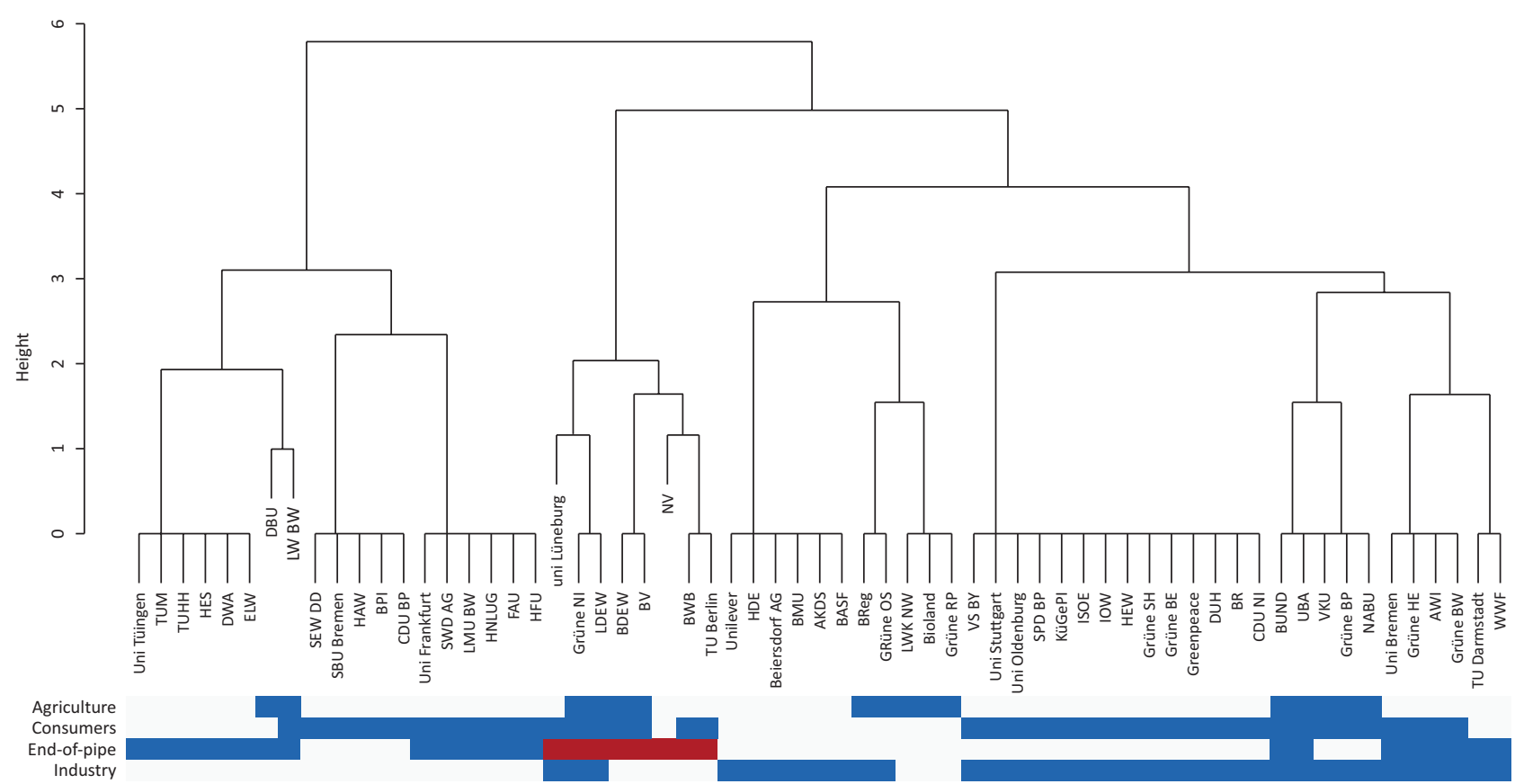

Policy network

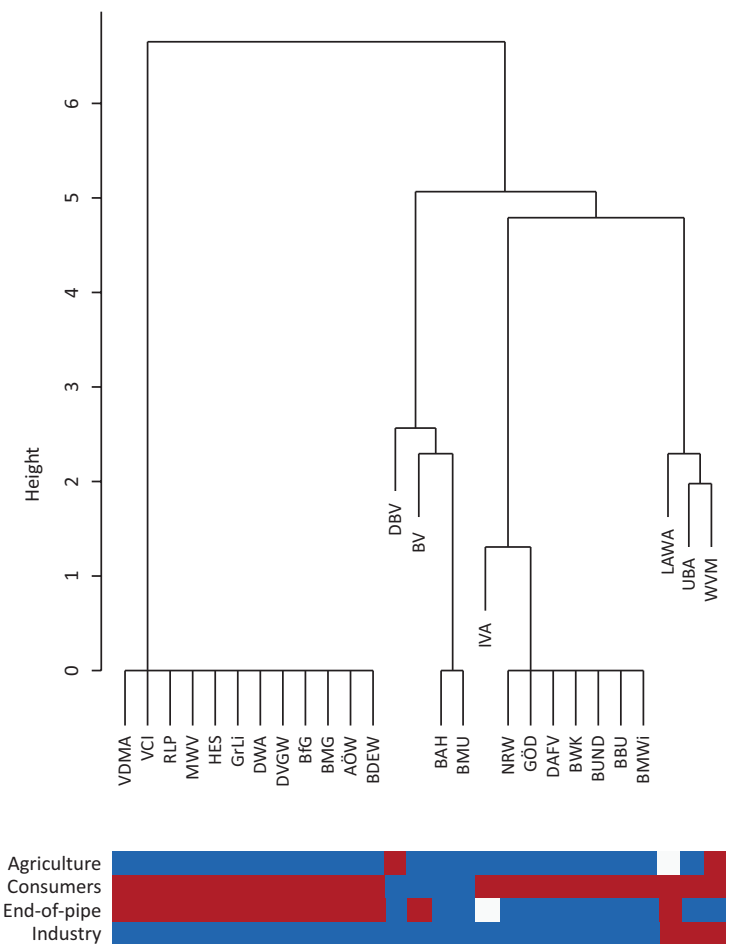

Figure 6. Cluster analysis. Notes: Blue $=$ agreement; red $=$ disagreement; white $=$ no statement. The colors illustrate actor's positioning on the policy solutions equivalent to Figure 4 . 


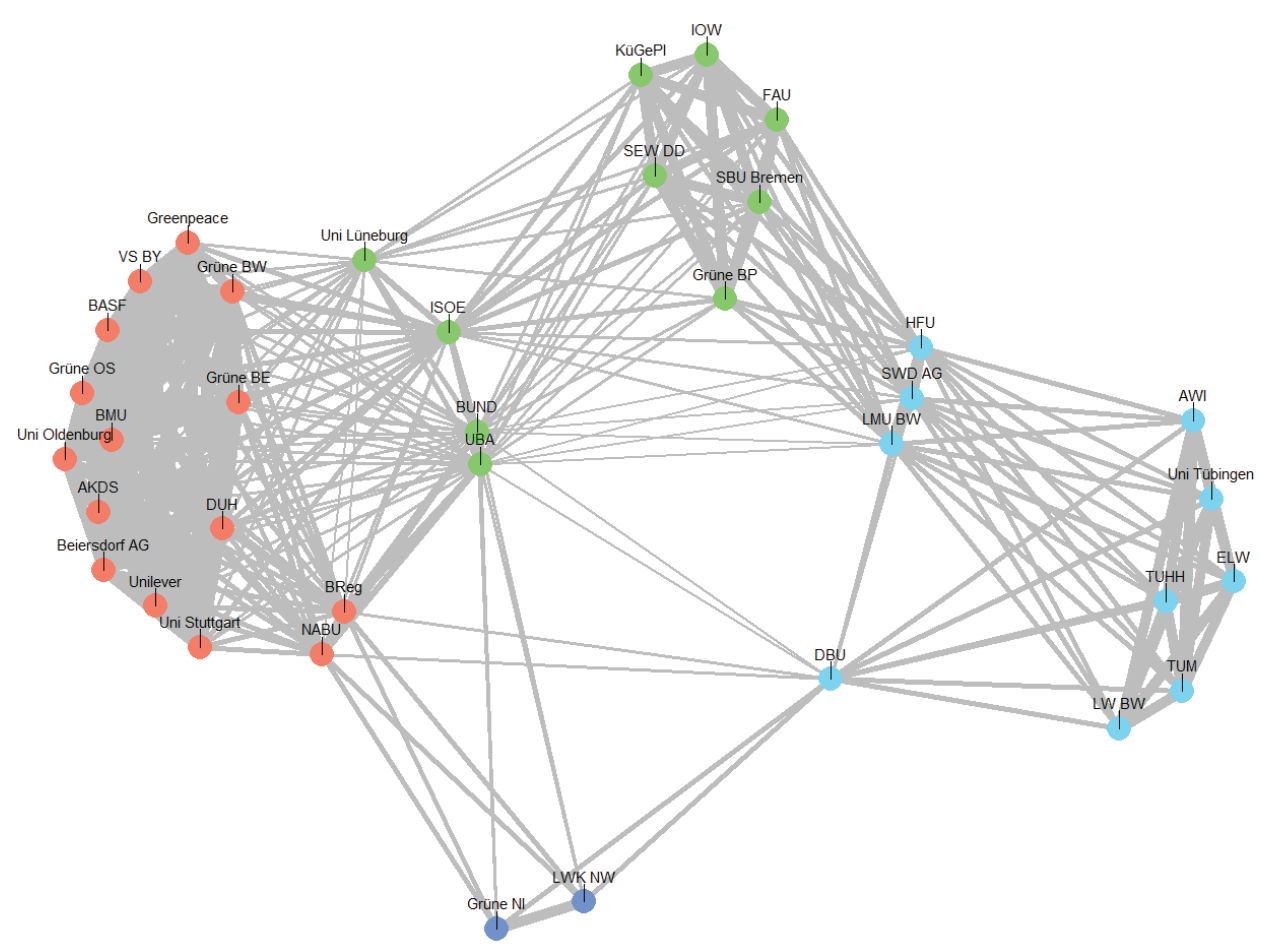

(a)

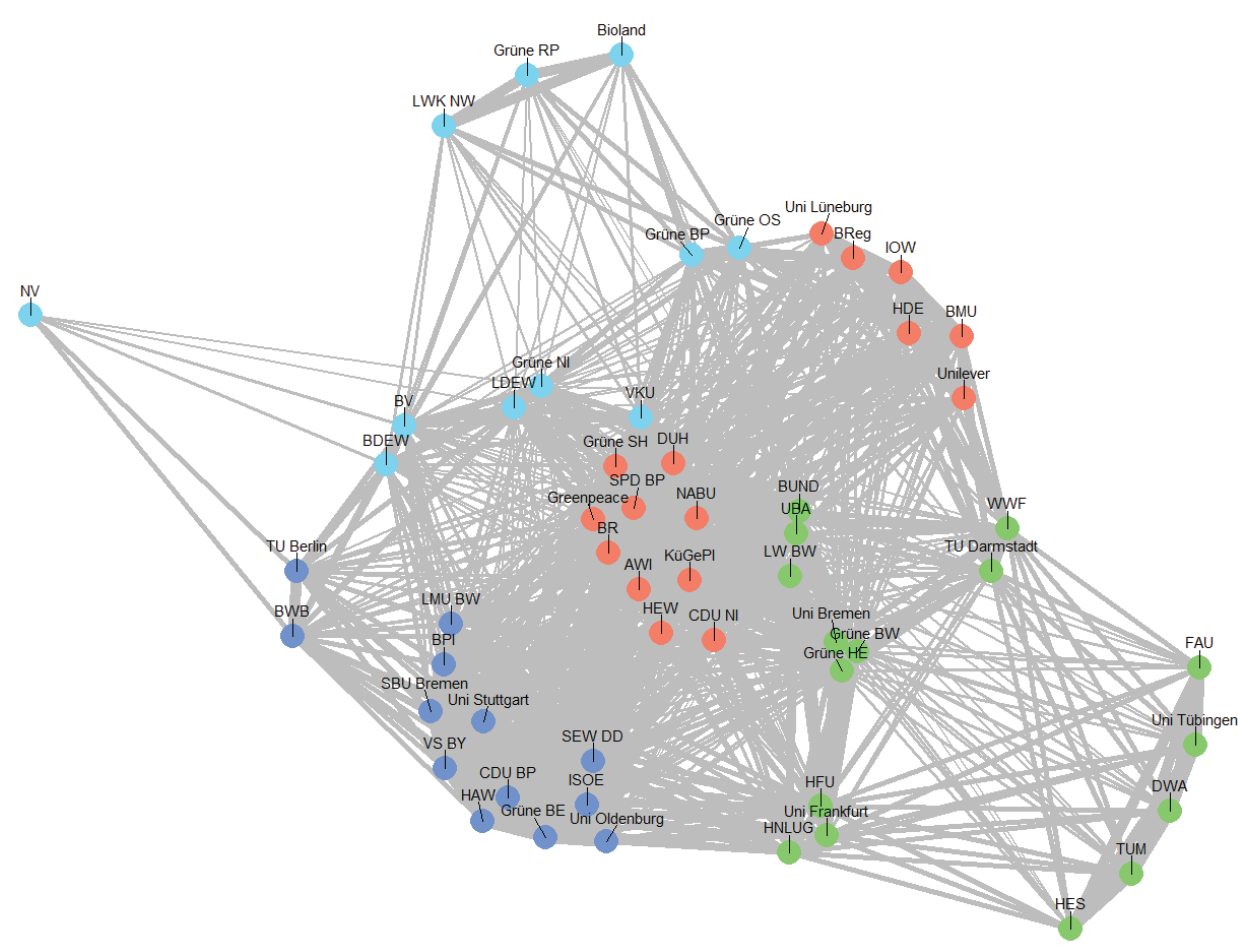

(b)

Figure 7. Comparing discourse networks over time. (a) January 2013-December 2014, (b) January 2015-March 2017. Notes: Node colors refer to different community membership; line width is dependent on edge weight (the more shared policy preferences, the thicker the line between two actors); actors have been positioned using the Fruchterman-Reingold algorithm. 
For our case, we find that the different analytic approaches lead to largely similar results, though some differences become manifest as well. First, results from policy and discourse network approaches differ in their emphasis on actor types. Whereas the share of actors with an interest in expanding or containing an issue is equal in the policy network, expanders dominate the discourse network. Results can be interpreted as a specificity of Germany, or corporatist states more generally, where organized interests (e.g., industry) have institutionalized access to policy formulation. Their lack of access to policy formulation may drive expanders to be particularly active in the policy discourse. Results could also be interpreted as specificities of methodological approaches. Studies that employ the discourse network approach could systematically emphasize expanders more than the policy network approach does. Future research is needed that compares expanders' and containers' access to policy venues (discourse/policy formulation) across corporatist and pluralist countries.

Secondly, both network approaches capture a high number of similarities among policy proposals, though some differences become manifest, as expected, when policies target consumers, i.e., voters. Such preferences are less visible in the policy than in the discourse network approach. Results may forewarn future research that policies targeting voters, e.g., demand-sided policies, are sensitive topics and therefore show up more prominently in discourse than in policy network approaches. Such dissimilarities also have implications for the analysis of coalitions. Coalitions are identified based on the shared preferences of actors. However, if actors strategically mask (or emphasize) their preferences depending on the venue (discourse/policy formulation), scholars should carefully evaluate how to integrate preference data into coalition analysis in order to produce results that are congruent across approaches.

Thirdly, the structures of policy and discourse networks are similar. Both networks are characterized by low polarization and a unitary structure. Although the differences in coalition structure are rather small, results indicate that discourse and policy network approaches highlight different games that actors play in discourses and policy formulation. The low share of disagreement statements in the discourse network suggests that actors focus on promoting their preferred policy proposals. In policy formulation, by contrast, actors seem additionally concerned with blocking unpopular proposals. The manner in which data are gathered emphasizes such differences because surveys explicitly ask respondents to indicate which policy proposals they support and reject, while media tends to report on policies that actors support.

Lastly, the structure of the discourse network differs between observation periods. Although the differences are not very strong, it is noteworthy that different time periods affect results. Collecting data for policy networks at different points in time would increase the accu- racy of results. As it remains challenging to survey political actors repeatedly, future research is needed which explores innovative data-collection methods that overcome the constraints of survey research (e.g., low participation) but still provide insider information about the policymaking process.

A key insight of our study is that some, albeit small, differences exist between policy and discourse network analyses. The discourse network approach emphasizes expanders, while the policy network approach masks actors' preferences for policies targeting voters. As differences are surprisingly low, our results suggest that both discourse and policy network data can be used to study the policy process and that results should not differ systematically. The conclusions apply to our case, but the generalizability is limited due to several reasons. First, the small- $N$ research design of this study possibly accentuates idiosyncrasies, i.e., characteristics that might be case-specific. For instance, the low level of polarization that the discourse network approach revealed might also stem from the fact that micropollution is a rather technical issue that actors have not yet politicized in the German media. Second, our discourse network analysis includes four concepts, whereas most of the published studies on discourse networks consider a larger number of concepts. The use of a limited number of concepts in our case could be one reason for the low level of polarization that we find within the discourse network. With more concepts, however, the analysis of coalition structures should be more fine-grained. In fact, most published studies on discourse networks find strongly polarized coalitions (Fisher, Waggle, \& Leifeld, 2013; Leifeld, 2013; Tosun \& Lang, 2016). In order to enhance external validity, future research comparing discourse and policy networks should use a more extensive number of concepts and apply a large- $\mathrm{N}$ and comparative research design.

To generate further theory-relevant insights, future research should identify the origin of differences between analytical approaches. Are differences a consequence of data-gathering techniques or an indication that different theoretical mechanisms guide the development of policy debates or policy formulation? To date, only a few comparative network studies exist (exceptions include Metz, 2017; Ylä-Anttila et al., 2018) to which we could compare our results in order to address this question. Ingold et al. (2020) follow a slightly different goal in their comparison of data on policy preferences that were gathered using surveys and coded consultations. They report differences in data on actors' policy preferences across data sources, in particular for policy losers, i.e., actors whose positions were not considered in the final policy decision. They can only speculate where changes come from, e.g., as losers may want to mask their political loss. Their study encounters the same difficulty as we do in identifying the origin of these differences. One possible conclusion is that both survey and media data can only approximate what happens during policy processes. 
However, future developments, e.g., e-democracy, could increase the transparency of this and thereby draw a sharper picture of policy change.

\section{Acknowledgments}

A special note of thanks goes to Karin Ingold, Jale Tosun and Eva Lieberherr, who supported this study. The authors would like to thank the Swiss National Science Foundation and the Ministerium für Wissenschaft, Forschung und Kunst Baden-Württemberg for their generous financial support (grant number 105217_140395, "How to explain instrument selection in complex policy processes" and grant number 33-7533 respectively). A previous version of this article was presented at the 2019 ECPR general conference. We thank the conference discussants and panel members for their helpful thoughts on our article. Finally, we thank the editor and anonymous reviewers for their constructive inputs.

\section{Conflict of Interests}

The authors declare no conflict of interests.

\section{Supplementary Material}

Supplementary material for this article is available online in the format provided by the authors (unedited).

\section{References}

Adam, S., \& Kriesi, H.-P. (2007). The network approach. In P. A. Sabatier (Ed.), Theories of the policy process (pp. 129-154). Boulder, CO: Westview Press.

Baumgartner, F. R., Berry, J. M., Hojnacki, M., Leech, B. L., \& Kimball, D. C. (2009). Lobbying and policy change. Chicago, IL: University of Chicago Press. https://doi. org/10.7208/chicago/9780226039466.001.0001

Binderkrantz, A. S., Christiansen, P. M., \& Pedersen, H. H. (2015). Interest group access to the bureaucracy, parliament, and the media. Governance, 28(1), 95-112. https://doi.org/10.1111/gove.12089

Börzel, T. A. (1998). Organizing Babylon: On the different conceptions of policy networks. Public Administration, 76(2), 253-273. https://doi.org/10.1111/14679299.00100

Bulkeley, H. (2000). Discourse coalitions and the Australian climate change policy network. Environment and Planning C: Government and Policy, 18(6), 727-748. https://doi.org/10.1068/c9905j

Christiansen, P. M., Mach, A., \& Varone, F. (2018). How corporatist institutions shape the access of citizen groups to policy-makers: Evidence from Denmark and Switzerland. Journal of European Public Policy, 25(4), 526-545. https://doi.org/10.1080/13501763. 2016.1268194

Cobb, R. W., \& Coughlin, J. F. (1998). Are elderly drivers a road hazard? Problem definition and polit- ical impact. Journal of Aging Studies, 12(4), 411-427. https://doi.org/10.1016/S0890-4065(98)90027-5

Easton, D. (1965). A framework for political analysis (2nd ed.). Englewood Cliffs, NJ: Prentice-Hall.

Fischer, M. (2014). Coalition structures and policy change in a consensus democracy. Policy Studies Journal, 42(3), 344-366. https://doi.org/10.1111/psj.12064

Fischer, M. (2017). Institutions and policy networks. In J. N. Victor, A. H. Montgomery, \& M. Lubell (Eds.), The Oxford handbook of political networks (pp. 301-325). Oxford: Oxford University Press.

Fischer, M., Angst, M., \& Maag, S. (2017). Coparticipation in the Swiss water forum network. International Journal of Water Resources Development, 2(1), 1-19. https://doi.org/10.1080/07900627. 2017.1374929

Fisher, D. R., Leifeld, P., \& Iwaki, Y. (2013). Mapping the ideological networks of American climate politics. Climatic Change, 116(3/4), 523-545. https://doi.org/ 10.1007/s10584-012-0512-7

Fisher, D. R., Waggle, J., \& Leifeld, P. (2013). Where does political polarization come from? Locating polarization within the U.S. climate change debate. American Behavioral Scientist, 57(1), 70-92. https://doi.org/ 10.1177/0002764212463360

Foucault, M. (1991). Die Ordnung des Diskurses [The order of discourse]. Frankfurt: Fischer.

Habermas, J. (1981). Theorie des kommunikativen Handelns [Theory of communicative action]. Frankfurt: Suhrkamp.

Habermas, J. (1996). Between facts and norms: Contributions to a discourse theory of law and democracy. Cambridge: Polity.

Hajer, M. A. (1993). Discourse coalitions and the institutionalization of practice: The case of acid rain in Britain. In F. Fischer \& J. Forester (Eds.), The argumentative turn in policy analysis and planning (pp. 51-84). Durham, NC: Duke University Press.

Henry, A. D. (2011). Ideology, power, and the structure of policy networks. Policy Studies Journal, 39(3), 361-383. https://doi.org/10.1111/j.1541-0072. 2011.00413.x

Howlett, M. (2002). Do networks matter? Linking policy network structure to policy outcomes: Evidence from four Canadian policy sectors 1990-2000. Canadian Journal of Political Science, 35(2), 235-267. https:// doi.org/10.1017/S0008423902778232

Ingold, K. (2011). Network structures within policy processes: Coalitions, power, and brokerage in Swiss climate policy. Policy Studies Journal, 39(3), 435-459. https://doi.org/10.1111/j.1541-0072.2011.00416.x

Ingold, K., \& Fischer, M. (2014). Drivers of collaboration to mitigate climate change: An illustration of Swiss climate policy over 15 years. Global Environmental Change, 24, 88-98. https://doi.org/10.1016/ j.gloenvcha.2013.11.021

Ingold, K., \& Gschwend, M. (2014). Science in policymaking: Neutral experts or strategic policy-makers? 
West European Politics, 37(5), 993-1018. https://doi. org/10.1080/01402382.2014.920983

Ingold, K., Varone, F., Kammerer, M., Metz, F., Kammermann, L., \& Strotz, C. (2020). Are responses to official consultations and stakeholder surveys reliable guides to policy actors' positions? Policy \& Politics, 48(2), 193-222. https://doi.org/10.1332/ $030557319 \times 15613699478503$

Jain, A. K., \& Dubes, R. C. (1988). Algorithms for clustering data. Upper Saddle River, NJ: Prentice-Hall.

Janning, F., Leifeld, P., Malang, T., \& Schneider, V. (2009). Diskursnetzwerkanalyse: Überlegungen zur Theoriebildung und Methodik [Discourse network analysis: Thoughts on theory development and methodology]. In T. Malang (Ed.), SpringerLink: Bücher. Politiknetzwerke: Modelle, Anwendungen und Visualisierungen [Policy networks: Models, applications and visualizations] (pp. 59-92). Wiesbaden: VS Verlag für Sozialwissenschaften and GWV Fachverlage $\mathrm{GmbH}$.

Jones, M. D., McBeth, M. K., \& Shanahan, E. A. (2014). Introducing the narrative policy framework. In M. D. Jones, E. A. Shanahan, \& M. K. McBeth (Eds.), The science of stories (pp. 1-25). New York, NY: Palgrave Macmillan.

Laumann, E. O., \& Knoke, D. (1987). The organizational state: Social choice in national policy domains. Madison, WI: University of Wisconsin Press.

Laumann, E. O., Pappi, F. U., \& Rossi, P. H. (1976). Networks of collective action: A perspective on community influence systems. New York, NY: Academic Press.

Leifeld, P. (2013). Reconceptualizing major policy change in the advocacy coalition framework: A discourse network analysis of German pension politics. Policy Studies Journal, 41(1), 169-198. https://doi.org/10.1111/ psj.12007

Leifeld, P. (2016). Policy debates as dynamic networks: German pension politics and privatization discourse. Frankfurt: Campus Verlag.

Leifeld, P. (2017). Discourse network analysis: Policy debates as dynamic networks. In J. N. Victor, A. H. Montgomery, \& M. Lubell (Eds.), The Oxford handbook of political networks (pp. 301-325). Oxford: Oxford University Press.

Leifeld, P., Gruber, J., \& Bossner, F. R. (2019). Discourse network analyzer manual: Version 2.0-beta24.jar with rDNA 2.1.16. Colchester: University of Essex. Retrieved from https://www.philipleifeld.com/ software/software.html

Leifeld, P., \& Haunss, S. (2012). Political discourse networks and the conflict over software patents in Europe. European Journal of Political Research, 51(3), 382-409. https://doi.org/10.1111/j.1475-6765. 2011.02003.x

Leifeld, P., \& Schneider, V. (2012). Information exchange in policy networks. American Journal of Political Science, 56(3), 731-744. https://doi.org/10.1111/ j.1540-5907.2011.00580.x
Levy, J. S. (2008). Case studies: Types, designs, and logics of inference. Conflict Management and Peace Science, 25(1), 1-18. https://doi.org/10.1080/ 07388940701860318

McCombs, M. E., \& Shaw, D. L. (1972). The agendasetting function of mass media. Public Opinion Quarterly, 36(2), 176-187.

Metz, F. (2017). From network structure to policy design in water protection: A comparative perspective on micropollutants in the Rhine River Riparian countries. Cham: Springer. https://doi.org/10.1007/978-3-31955693-2

Metz, F., \& Ingold, K. (2017). Politics of the precautionary principle: Assessing actors' preferences in water protection policy. Policy Sciences, 50(4), 721-743. https://doi.org/10.1007/s11077-017-9295-z

Moe, T. M. (1990). Political institutions: The neglected side of the story. Journal of Law, Economics and Organization, 6, 213-253.

Mühlböck, M., \& Tosun, J. (2018). Responsiveness to different national interests: Voting behaviour on genetically modified organisms in the Council of the European Union. JCMS: Journal of Common Market Studies, 56(2), 385-402. https://doi.org/10.1111/ jcms.12609

Nagel, M. (2016). Polarisierung im politischen Diskurs [Polarization in the political discourse?]. Wiesbaden: Springer Fachmedien Wiesbaden. https://doi.org/ 10.1007/978-3-658-11225-7

Reichardt, J., \& Bornholdt, S. (2006). Statistical mechanics of community detection. Physical Review E, 2006(74). https://doi.org/10.1103/PhysRevE.74. 016110

Sabatier, P. A. (1987). Knowledge, policy-oriented learning, and policy change. Knowledge, 8(4), 649-692. https://doi.org/10.1177/0164025987008004005

Sabatier, P. A., \& Jenkins-Smith, H. C. (1999). The advocacy coalition framework: An assessment. In P. A. Sabatier (Ed.), Theories of the policy process (pp. 117-166). Boulder, CO: Westview Press.

Schattschneider, E. E. (1960). The semi-sovereign people: A realist's view of democracy in America. New York, NY: Holt, Rinehart and Winston.

Tosun, J., \& Lang, A. (2016). The politics of hydraulic fracturing in Germany: Party competition at different levels of government. In C. M. Weible, T. Heikkila, K. Ingold, \& M. Fischer (Eds.), Policy debates on hydraulic fracturing (pp. 177-200). New York, NY: Palgrave Macmillan.

Tosun, J., \& Schaub, S. (2017). Mobilization in the European public sphere: The struggle over genetically modified organisms. Review of Policy Research, 34(3), 310-330.

Tosun, J., Schaub, S., \& Fleig, A. (2020). What determines regulatory preferences? Insights from micropollutants in surface waters. Environmental Science \& Policy, 106, 136-144. https://doi.org/10.1016/ j.envsci.2020.02.001 
Trebilcock, M. J., \& Hartle, D. G. (1982). The choice of governing instrument. International Review of Law and Economics, 2(1), 29-46. https://doi.org/ 10.1016/0144-8188(82)90012-6

Triebskorn, R., Blaha, L., Gallert, C., Giebner, S., Hetzenauer, H., Köhler, H.-R, . . . Wilhelm, S. (2019). Freshwater ecosystems profit from activated carbonbased wastewater treatment across various levels of biological organisation in a short timeframe. Environmental Sciences Europe, 31(1), 20. https://doi.org/ 10.1186/s12302-019-0267-0

Weible, C. M., Sabatier, P. A., \& McQueen, K. (2009). Themes and variations: Taking stock of the advocacy coalition framework. Policy Studies Journal, 37(1), 121-140.
Wlezien, C. (2004). Patterns of representation: Dynamics of public preferences and policy. The Journal of Politics, 66(1), 1-24. https://doi.org/10.1046/j.14682508.2004.00139.x

Wolfe, M., Jones, B. D., \& Baumgartner, F. R. (2013). A failure to communicate: Agenda setting in media and policy studies. Political Communication, 30(2), 175-192. https://doi.org/10.1080/10584609. 2012.737419

Ylä-Anttila, T., Gronow, A., Stoddart, M. C. J., Broadbent, J., Schneider, V., \& Tindall, D. B. (2018). Climate change policy networks: Why and how to compare them across countries. Energy Research \& Social Science, 45, 258-265. https://doi.org/10.1016/ j.erss.2018.06.020

\section{About the Authors}

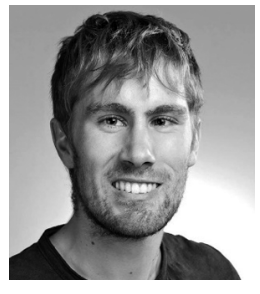

Simon Schaub is a Research Fellow at the Institute of Political Science at Heidelberg University. His research centers on environmental policy and risk governance, with a focus on water issues. He is part of the interdisciplinary project Effect-Net, which aims to provide insights into the cross-linking of governance and the ecological impact of micropollutants in water. Currently, he is writing his PhD on the governance of water pollution.

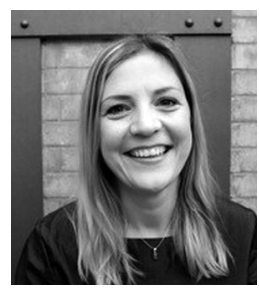

Florence Metz is an Assistant Professor in the Department of Governance \& Technology for Sustainability (CSTM) of the University of Twente in the Netherlands. She holds a PhD in public policy from the University of Bern in Switzerland. As a Post-Doctoral Researcher, she worked at the Natural Resource Policy Group of ETH Zürich and at the Centre for Development and Environment of the University of Bern. Her research is embedded within the broader theoretical questions of public policy research. With the aim of contributing to more sustainable policy results, she analyzes the design of policies and the social mechanisms behind decision-making. 